\title{
Rate/state Coulomb stress transfer model for the CSEP Japan seismicity forecast
}

\author{
Shinji Toda ${ }^{1}$ and Bogdan Enescu ${ }^{2}$ \\ ${ }^{1}$ Disaster Prevention Research Institute (DPRI), Kyoto University, Gokasho, Uji, Kyoto 611-0011, Japan \\ ${ }^{2}$ National Research Institute for Earth Science and Disaster Prevention (NIED), 3-1 Tennodai, Tsukuba, Ibaraki 305-0006, Japan
}

(Received June 25, 2010; Revised January 13, 2011; Accepted January 13, 2011; Online published March 4, 2011)

\begin{abstract}
Numerous studies retrospectively found that seismicity rate jumps (drops) by coseismic Coulomb stress increase (decrease). The Collaboratory for the Study of Earthquake Prediction (CSEP) instead provides us an opportunity for prospective testing of the Coulomb hypothesis. Here we adapt our stress transfer model incorporating rate and state dependent friction law to the CSEP Japan seismicity forecast. We demonstrate how to compute the forecast rates of large shocks in 2009 using the large earthquakes during the past 120 years. The time dependent impact of the coseismic stress perturbations explains qualitatively well the occurrence of the recent moderate size shocks. Such ability is partly similar to that of statistical earthquake clustering models. However, our model differs from them as follows: the off-fault aftershock zones can be simulated using finite fault sources; the regional areal patterns of triggered seismicity are modified by the dominant mechanisms of the potential sources; the imparted stresses due to large earthquakes produce stress shadows that lead to a reduction of the forecasted number of earthquakes. Although the model relies on several unknown parameters, it is the first physics based model submitted to the CSEP Japan test center and has the potential to be tuned for short-term earthquake forecasts.
\end{abstract}

Key words: Coulomb stress change, rate and state friction, seismicity forecast, CSEP Japan.

\section{Introduction}

A principal tenet of the Coulomb hypothesis is that stress increases promote, and decreases inhibit fault failure. In support of such a simple hypothesis, a growing number of studies have found that seismicity rates climb where the Coulomb stress increases and fall where the Coulomb stress drops (e.g., Steacy et al., 2005 and references therein). However, except a couple of prospective suggestions for possible occurrence of subsequent ruptures (Barka, 1999; McCloskey et al., 2005), the majority of the papers focused on retrospective evaluation, which may permit unintentional bias to enter into data interpretation. Further, for the near future applications, such retrospective performance does not contribute to earthquake disaster mitigation. The probability rate for triggered seismicity in particular has been proved to be highest immediately after a mainshock (e.g., Parsons, 2002), as theoretically suggested by the rate/state friction law (Dieterich, 1994).

The Collaboratory for the Study of Earthquake Predictability (CSEP) instead provides us opportunities to execute fair tests, ensuring "transparency", "controlled environment", "model comparability", and "reproducibility" (Schorlemmer and Gerstenberger, 2007). The CSEP also steps forward for improving our understanding about the physics and predictability of earthquakes through

Copyright (c) The Society of Geomagnetism and Earth, Planetary and Space Sciences (SGEPSS); The Seismological Society of Japan; The Volcanological Society of Japan; The Geodetic Society of Japan; The Japanese Society for Planetary Sciences; TERRAPUB.

doi:10.5047/eps.2011.01.004 such rigorous and prospective testing (Schorlemmer et al., 2009). Here we adopt our rate/state Coulomb stress transfer model for the Japan's mainland testing region, which is one of the CSEP Japan test regions. We apply our model for the "1 year" and "3 years" forecasting classes. Since the secular stressing rate inland Japan is much lower than in regions near the subduction zones, the effects of coseismic stress changes due to large earthquakes last longer. We thus assume that our model is appropriate for the mainland regions, focusing on shallow crustal earthquakes, rather than the entire Japanese islands that include deeper earthquakes. In this paper, we introduce our stress-based model and examples of the outputs, and then discuss possible advantages, disadvantages and limitations of the model.

\section{Forecast Model}

\subsection{Overall approach}

We follow the fundamental process for seeking time- and space-dependent seismicity incorporating stress perturbations developed by Toda et al. (2005), which retrospectively applied their method to the evolution of seismicity in southern California and then roughly reproduced the time-spacedependent seismicity patterns. Considering several issues of the parameters setting raised by Toda et al. (2005) and recent papers (e.g., Hainzl et al., 2009), here we slightly modify the methodology of Toda et al. (2005) to fit the CSEP Japan rules. The final goal of our forecast model, following the CSEP rules, is to seek the number of $M \geq 5.0$ shocks during the test periods of one year and three years, respec- 


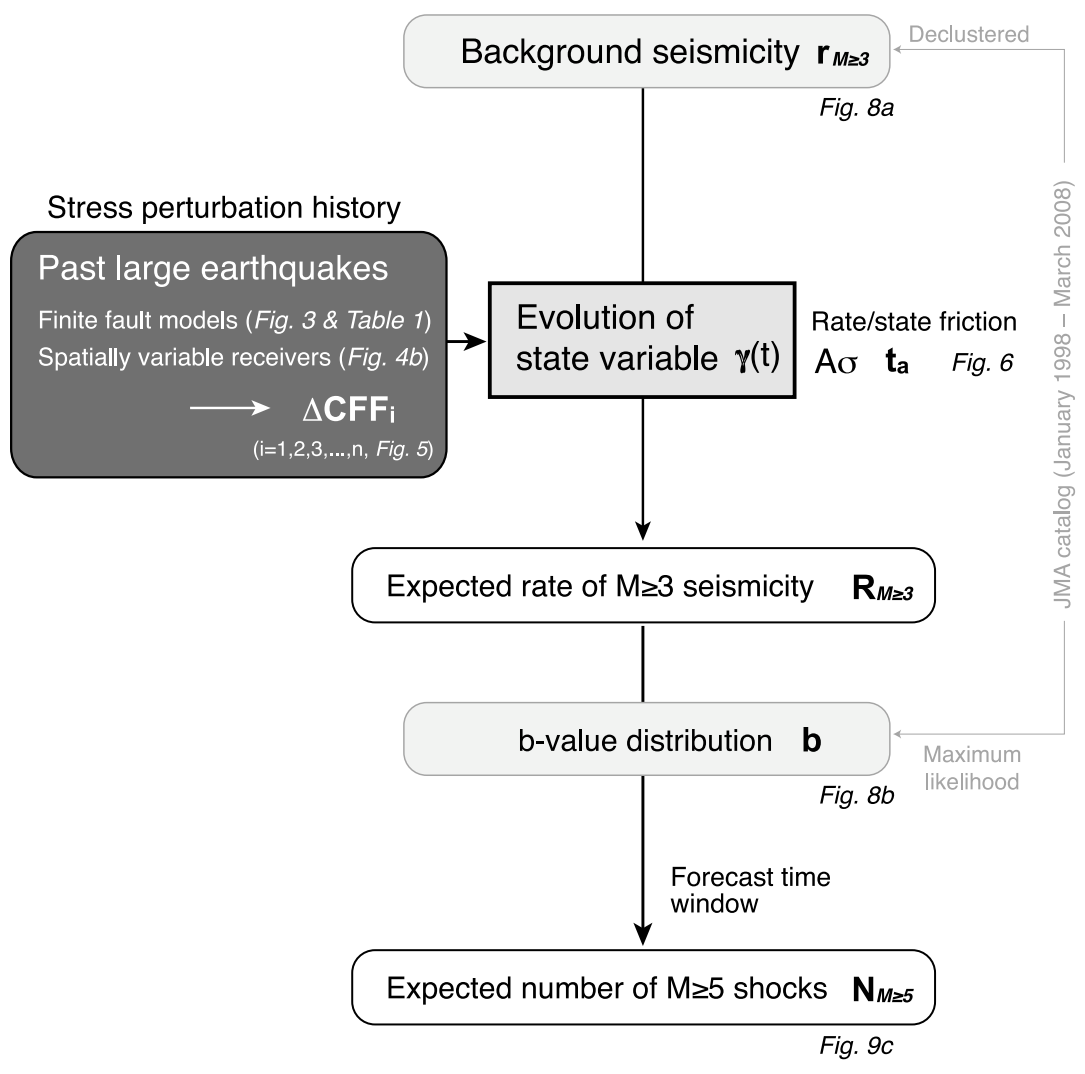

Fig. 1. Conceptual procedure to seek the expected number of large earthquakes in the rate/state stress transfer model.

tively (here we use " $M$ " as magnitude determined by the Japan Meteorological Agency, JMA).

The overall procedure to seek the number of expected large earthquakes is simply illustrated in Fig. 1. We follow this flowchart at each node of the CSEP Japan grid, which allows us to map the time-dependent seismicity distribution. During the computational process, we use matrices to handle spatial variations (Fig. 2). The core of our model is the incorporation of stress perturbations caused by the past large earthquakes. We compute the coseismic Coulomb stress changes $(\triangle \mathrm{CFF})$ using available fault models and then update the time-dependent state variable $\gamma$, which is the key parameter to directly control the seismicity. In a time series representation, $\triangle \mathrm{CFF}$ are step functions, whereas $\gamma$ at a node decays and recovers gradually on the basis of rate/state friction framework (Fig. 2). In our model, coseismic stress changes do not simply turn on or off seismicity; rather, the background seismicity rate is enhanced by stress increases or suppressed by stress decreases. Thus, the assumed background seismicity matrices are prescribed and altered by $\gamma$ associated with the stress perturbations. Taking the $b$-value distribution into account, we finally translate the rate of all shocks into the rate of expected number of large earthquakes during the forecast time-window lengths of one and three years (Fig. 2).

\subsection{Coulomb stress changes and parameters}

Again, the key feature of our method is to quantify the stress perturbation effect in terms of seismicity rate changes. To do that, we calculate the static Coulomb stress change $\triangle$ CFF caused by each mainshock in an elastic halfspace of Okada (1992) with Poisson's ratio of 0.25 and a shear modulus of $32 \mathrm{GPa} . \triangle \mathrm{CFF}$ is computed using the following equation, with simplifying assumptions to account for pore pressure effects (King et al., 1994)

$$
\Delta \mathrm{CFF}=\Delta \tau+\mu^{\prime} \Delta \sigma
$$

where $\Delta \tau$ is the shear stress change on a given fault plane (positive in the direction of fault slip), $\Delta \sigma$ is the faultnormal stress change (positive when unclamped), and $\mu^{\prime}$ is the effective coefficient of friction. To minimize uncertainties and calculation loads, we use an effective coefficient of friction, $\mu^{\prime}=0.4$, assumed to be constant for all faults. The maximum $\triangle \mathrm{CFF}$ over the seismogenic depth of $5-15 \mathrm{~km}$ (which we sample at 5,10 and $15 \mathrm{~km}$ ) is calculated on the assumption that seismicity will occur at the depth location where the stress is most increased toward failure. To calculate $\triangle \mathrm{CFF}$ at all nodes of the CSEP Japan grid, the source faults and the slip directions on which Coulomb stress changes are resolved ("receiver faults" hereinafter) must be specified. The following two sections explain the seismic sources associated with inland large earthquakes and the receiver faults.

\subsection{Seismic sources}

According to the rate/state friction of Dieterich (1994), the longer the time passes since a mainshock, the lesser the effect of its stress perturbation on seismicity. In other words, the older earthquakes are less important as stress perturbation sources. Although several papers discussed that the current high seismicity in some areas might reflect the long-lived aftershock activity after the historic earthquakes that occurred in 1800s (e.g., Mikumo et al., 1988), 


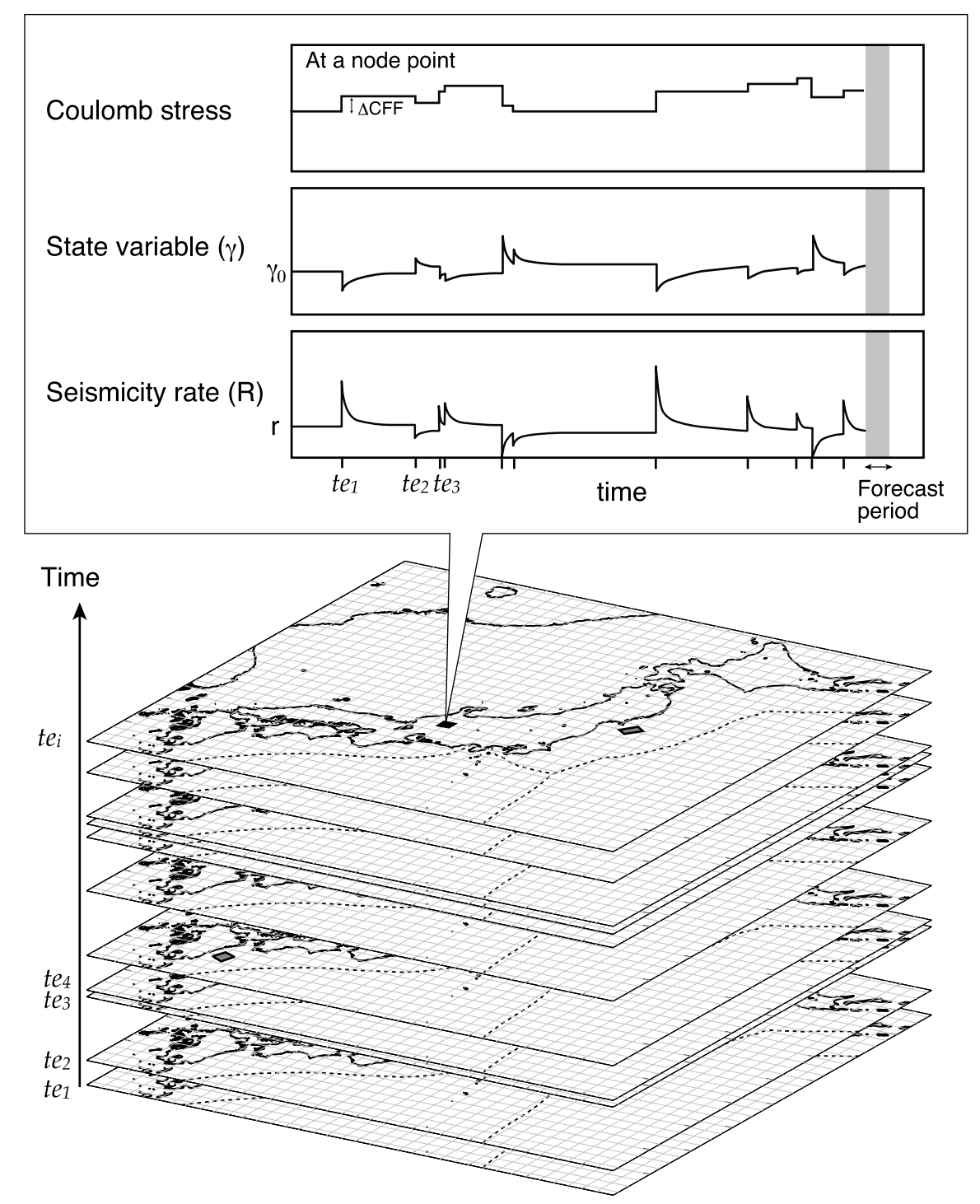

Fig. 2. Schematic diagrams of stress perturbation history due to recent large earthquakes and corresponding changes of state variable and seismicity rate. Spatial heterogeneities of stress changes with time stamp, seismicity rates, and other parameters are treated as matrices (bottom panel). Occurrence times of the $i$-th large earthquake are denoted as $t e_{i}$.

here we basically consider for our Coulomb stress computations the seismic sources of relatively large earthquakes that occurred after 1923, which is the beginning year of the JMA earthquake catalog that covers the whole territory of Japan. We include, however, the source of the $1891 M=8.0$ Nobi earthquake, which is historically the largest inland shock in Japan and widely impacted the regional seismicity. As basic selection criteria, we consider the earthquake sources for events with magnitudes $M \geq 6.5$, which occurred within an "expanded" test area (rectangle area defined by the maximum and minimum longitudes and latitudes of the test area) and are shallower than $30 \mathrm{~km}$. However, we also included some events with magnitudes slightly smaller than 6.5 in our source list (Table 1), since they were crustal earthquakes and had the fault source model available (e.g., May 13, $1997 M=6.4$ Kagoshima-ken-hokuseibu earthquake). Figure 3 and Table 1 show our 67 earthquake sources, about a half of which are already modeled as variable slip distributions, while for the others we applied a simple uniform slip model using the empirical relations of Wells and
Coppersmith (1994) (annotated as "empirical" in Table 1). Most of the variable slip models are from the references in Sato et al. (1989, 1999), Sato and Koketsu (2005), and Mai (2007) that already provide us their parametric tables.

\subsection{Receiver faults}

The Coulomb stress calculation requires defining the geometry of the receiver fault and its slip direction to resolve the associated stress tensors. There are two usual approaches to seek the $\triangle \mathrm{CFF}$ matrices, taking the types of receiver faults into account. One is the "specified fault" approach, in which it is simply assumed that the receiver faults have the same strike, dip, and rake as the mainshock source fault, considered as the regional, dominant faulting mechanism. The other is the "optimally oriented fault planes for failure (King et al., 1994)" approach, in which the receiver faults are determined in such a way as to maximize the $\triangle \mathrm{CFF}$ value, taking into account both the assumed regional pre-mainshock stress tensor and the stress perturbation tensor. This approach normally maximizes $\triangle \mathrm{CFF}$ in particular under lower differential stress conditions, and of- 
Table 1. List of earthquakes, and their source models, used for calculating coseismic Coulomb stress changes. $M$ in the table header refers to the JMA magnitude. We basically consider large earthquakes $(M \geq 6.5)$ that occurred after 1923, which is the beginning year of the JMA earthquake catalog. However we include the source of the 1891 Nobi earthquake, which is historically the largest inland shock in Japan and widely impacted the regional seismicity, and a few destructive inland shocks slightly smaller than $M$ 6.5. See more details in the text.

\begin{tabular}{|c|c|c|c|c|c|c|c|c|c|c|c|}
\hline ID & Year & Month & Day & Hour & Minute & Year (decimal) & $M$ & Lon. $\left({ }^{\circ}\right)$ & Lat. $\left(^{\circ}\right)$ & Name & Fault model \\
\hline 1 & 1891 & 10 & 28 & 6 & 38 & 1891.82211 & 8.0 & - & - & Nobi & Mikumo and Ando (1976) \\
\hline 2 & 1923 & 9 & 1 & 11 & 58 & 1923.66666 & 7.9 & 139.136 & 35.331 & Kanto & Wald and Somerville (1995) \\
\hline 3 & 1925 & 5 & 23 & 11 & 9 & 1925.39005 & 6.8 & 134.835 & 35.563 & Kita-Tajima & Empirical \\
\hline 4 & 1927 & 3 & 7 & 18 & 27 & 1927.18007 & 7.3 & 134.931 & 35.632 & Kita-Tango & Matsu'ura (1977) \\
\hline 5 & 1930 & 11 & 26 & 4 & 2 & 1930.90121 & 7.3 & 138.974 & 35.043 & Kita-Izu & Abe (1978) \\
\hline 6 & 1931 & 9 & 21 & 11 & 19 & 1931.72135 & 6.9 & 139.248 & 36.158 & Nishi-Saitama & Abe (1974a) \\
\hline 7 & 1939 & 5 & 1 & 15 & 0 & 1939.33025 & 6.8 & 139.600 & 39.997 & Oga & Yoshioka (1974) \\
\hline 8 & 1940 & 8 & 2 & 0 & 8 & 1940.58592 & 7.5 & 139.817 & 44.359 & Shakotan Hanto Oki & Satake (1986) \\
\hline 9 & 1943 & 9 & 10 & 17 & 36 & 1943.69195 & 7.2 & 134.184 & 35.473 & Tottori & Sato (1973) \\
\hline 10 & 1944 & 12 & 7 & 13 & 35 & 1944.93516 & 7.9 & 136.175 & 33.573 & Tokankai & Satake (1993) \\
\hline 11 & 1945 & 1 & 13 & 3 & 38 & 1945.03327 & 6.8 & 137.114 & 34.703 & Mikawa & Kikuchi et al. (2003) \\
\hline 12 & 1946 & 12 & 21 & 4 & 19 & 1946.96969 & 8.0 & 135.849 & 32.935 & Nankai & Satake (1993) \\
\hline 13 & 1948 & 6 & 28 & 16 & 13 & 1948.49193 & 7.1 & 136.291 & 36.172 & Fukui & Ichinose et al. (2005) \\
\hline 14 & 1961 & 8 & 19 & 14 & 33 & 1961.63137 & 7.0 & 136.700 & 36.112 & Kita-Mino & Takeo (1990) \\
\hline 15 & 1962 & 4 & 30 & 11 & 26 & 1962.32711 & 6.5 & 141.138 & 38.740 & Miyagi-ken-hokubu & Empirical \\
\hline 16 & 1963 & 3 & 27 & 6 & 34 & 1963.23347 & 6.9 & 135.792 & 35.815 & Wakasa-wan & Abe $(1974 b)$ \\
\hline 17 & 1964 & 5 & 7 & 16 & 58 & 1964.34964 & 6.9 & 138.668 & 40.397 & Ogahanto-oki & Fukao and Furumoto (1975) \\
\hline 18 & 1964 & 6 & 16 & 13 & 1 & 1964.45871 & 7.5 & 139.212 & 38.370 & Niigata & Matsuhashi et al. (1987) \\
\hline 19 & 1969 & 9 & 9 & 14 & 15 & 1969.68883 & 6.6 & 137.067 & 35.783 & Gifu-ken-chubu & Takeo (1990) \\
\hline 20 & 1974 & 5 & 9 & 8 & 33 & 1974.35142 & 6.9 & 138.800 & 34.567 & Izu-hanto-oki & Takeo (1990) \\
\hline 21 & 1978 & 1 & 14 & 12 & 24 & 1978.03701 & 7.0 & 139.250 & 34.767 & Izu-Oshima-kinkai & Okada (1978) \\
\hline 22 & 1978 & 6 & 12 & 17 & 14 & 1978.44550 & 7.4 & 142.167 & 38.150 & Miyagi-ken-oki & Yamanaka and Kikuchi (2004) \\
\hline 23 & 1980 & 6 & 29 & 16 & 20 & 1980.49468 & 6.7 & 139.233 & 34.917 & Izu-hanto-toho-oki & Takeo (1988) \\
\hline 24 & 1983 & 5 & 26 & 11 & 59 & 1983.39836 & 7.7 & 139.073 & 40.360 & Nihonkai-chubu & Fukuyama and Irikura (1986) \\
\hline 25 & 1984 & 9 & 14 & 8 & 48 & 1984.70463 & 6.8 & 137.557 & 35.825 & Nagano-ken-seibu & Takeo and Mikami (1987) \\
\hline 26 & 1993 & 2 & 7 & 22 & 27 & 1993.10386 & 6.6 & 137.297 & 37.657 & Noto-hanto-oki & Empirical \\
\hline 27 & 1993 & 7 & 12 & 22 & 17 & 1993.52821 & 7.8 & 139.180 & 42.782 & Hokkaido-nansei-oki & Tanioka et al. (1995) \\
\hline 28 & 1995 & 1 & 7 & 7 & 37 & 1995.01730 & 7.2 & 142.305 & 40.223 & Sanriku-haruka & Empirical \\
\hline 29 & 1995 & 1 & 17 & 5 & 46 & 1995.04446 & 7.3 & 135.035 & 34.598 & Hygoken-nanbu (Kobe) & Wald (1996) \\
\hline 30 & 1995 & 12 & 30 & 21 & 11 & 1995.99626 & 6.5 & 143.752 & 40.700 & Aomori-ken-toho-oki & Empirical \\
\hline 31 & 1996 & 2 & 17 & 0 & 22 & 1996.12895 & 6.8 & 142.548 & 37.309 & Fukushima-oki & Empirical \\
\hline 32 & 1996 & 10 & 19 & 23 & 44 & 1996.80216 & 6.9 & 132.008 & 31.799 & Hyuganada & Yagi et al. (1998) \\
\hline 33 & 1996 & 12 & 3 & 7 & 17 & 1996.92349 & 6.7 & 131.680 & 31.770 & Hyuganada & Yagi et al. (1998) \\
\hline 34 & 1997 & 3 & 26 & 17 & 31 & 1997.23198 & 6.6 & 130.359 & 31.973 & Kagoshima-ken-hokuseibu & Horikawa (2001) \\
\hline 35 & 1997 & 5 & 13 & 14 & 38 & 1997.36170 & 6.4 & 130.303 & 31.948 & Kagoshima-ken aftershock & Horikawa (2001) \\
\hline 36 & 1997 & 6 & 25 & 18 & 50 & 1997.48127 & 6.6 & 131.666 & 34.441 & Yamaguchi-ken-hokubu & Ide (1999) \\
\hline 37 & 1999 & 1 & 24 & 9 & 37 & 1999.06407 & 6.6 & 131.290 & 30.569 & Tanegashima & Empirical \\
\hline 38 & 2000 & 1 & 28 & 23 & 21 & 2000.07659 & 7.0 & 146.744 & 43.008 & Nemuro-oki & Empirical \\
\hline 39 & 2000 & 7 & 1 & 23 & 21 & 2000.50012 & 6.5 & 139.194 & 34.190 & Kozu-shima & Empirical \\
\hline 40 & 2000 & 7 & 30 & 21 & 25 & 2000.58013 & 6.5 & 139.411 & 33.971 & Kozu-shima & Empirical \\
\hline 41 & 2000 & 10 & 6 & 13 & 30 & 2000.76540 & 7.3 & 133.349 & 35.274 & Tottori-ken-seibu & Iwata and Sekiguchi (2002) \\
\hline 42 & 2001 & 3 & 24 & 15 & 27 & 2001.22627 & 6.7 & 132.694 & 34.132 & Geiyo & Sekiguchi and Iwata (2002) \\
\hline 43 & 2003 & 5 & 26 & 18 & 24 & 2003.39909 & 7.1 & 141.651 & 38.821 & Sanriku-Minami & GSI (2003) \\
\hline 44 & 2003 & 7 & 26 & 7 & 13 & 2003.56482 & 6.4 & 141.171 & 38.405 & Miyagi-ken-hokubu & Hikima and Koketsu (2004) \\
\hline 45 & 2003 & 9 & 26 & 7 & 26 & 2003.73430 & 8.0 & 144.078 & 41.779 & Tokachi-oki & Tanioka et al. (2004) \\
\hline 46 & 2003 & 9 & 29 & 11 & 36 & 2003.74328 & 6.5 & 144.553 & 42.360 & Tokachi-oki aftershock & Empirical \\
\hline 47 & 2003 & 10 & 31 & 10 & 6 & 2003.83072 & 6.8 & 142.696 & 37.832 & Fukushima-oki & Empirical \\
\hline 48 & 2004 & 5 & 30 & 5 & 56 & 2004.41135 & 6.7 & 141.859 & 34.108 & - & Empirical \\
\hline 49 & 2004 & 9 & 5 & 19 & 7 & 2004.68117 & 7.1 & 136.798 & 33.033 & Kii-hanto-oki & Empirical \\
\hline 50 & 2004 & 9 & 5 & 23 & 57 & 2004.68172 & 7.4 & 137.141 & 33.138 & Kii-hanto-oki & Empirical \\
\hline 51 & 2004 & 9 & 7 & 8 & 29 & 2004.68993 & 6.5 & 137.293 & 33.209 & Kii-hanto-oki & Empirical \\
\hline 52 & 2004 & 10 & 23 & 17 & 56 & 2004.81245 & 6.8 & 138.867 & 37.292 & Chuetsu & Hikima and Koketsu (2005) \\
\hline 53 & 2004 & 10 & 23 & 18 & 34 & 2004.82257 & 6.1 & 138.930 & 37.306 & Chuetsu aftershock & Hikima and Koketsu (2005) \\
\hline 54 & 2004 & 11 & 29 & 3 & 32 & 2004.91211 & 7.1 & 145.275 & 42.946 & Nemuro & Empirical \\
\hline 55 & 2004 & 12 & 6 & 23 & 15 & 2004.93352 & 6.9 & 145.343 & 42.848 & Nemuro aftershock & Empirical \\
\hline 56 & 2005 & 1 & 19 & 15 & 11 & 2005.05101 & 6.8 & 142.019 & 33.937 & - & Empirical \\
\hline 57 & 2005 & 3 & 20 & 10 & 53 & 2005.21479 & 7.0 & 130.176 & 33.739 & Fukuoka-ken-sehio-oki & Horikawa (2006) \\
\hline 58 & 2005 & 8 & 16 & 11 & 46 & 2005.62283 & 7.2 & 142.278 & 38.150 & Miyagi-ken-oki & GSI (2005) \\
\hline
\end{tabular}


Table 1. (continued).

\begin{tabular}{|c|c|c|c|c|c|c|c|c|c|c|c|}
\hline ID & Year & Month & Day & Hour & Minute & Year (decimal) & $M$ & Lon. $\left({ }^{\circ}\right)$ & Lat. $\left(^{\circ}\right)$ & Name & Fault model \\
\hline 59 & 2005 & 11 & 15 & 6 & 38 & 2005.87139 & 7.2 & 144.945 & 38.027 & Sanriku & Empirical \\
\hline 60 & 2005 & 12 & 2 & 22 & 13 & 2005.91971 & 6.6 & 142.353 & 38.073 & Miyagi-oki & Empirical \\
\hline 61 & 2007 & 3 & 25 & 9 & 41 & 2007.22835 & 6.9 & 136.686 & 37.221 & Noto Hanto & Awata et al. (2008) \\
\hline 62 & 2007 & 7 & 16 & 10 & 13 & 2007.53778 & 6.8 & 138.609 & 37.557 & Chuetsu-oki & GSI (2007) \\
\hline 63 & 2008 & 5 & 8 & 1 & 45 & 2008.35064 & 7.0 & 141.608 & 36.228 & Kashima-nada & Empirical \\
\hline 64 & 2008 & 6 & 14 & 8 & 43 & 2008.45274 & 7.2 & 140.881 & 39.030 & Iwate-Miyagi nairiku & Takada et al. (2009) \\
\hline 65 & 2008 & 7 & 19 & 11 & 39 & 2008.54890 & 6.9 & 142.264 & 37.521 & Fukushima-ken-oki & Empirical \\
\hline 66 & 2008 & 9 & 11 & 9 & 20 & 2008.69648 & 7.1 & 144.151 & 41.776 & Tokachioki aftershock & Empirical \\
\hline 67 & 2008 & 12 & 20 & 19 & 29 & 2008.97142 & 6.6 & 142.700 & 36.531 & Fukushima-ken-oki & Empirical \\
\hline
\end{tabular}

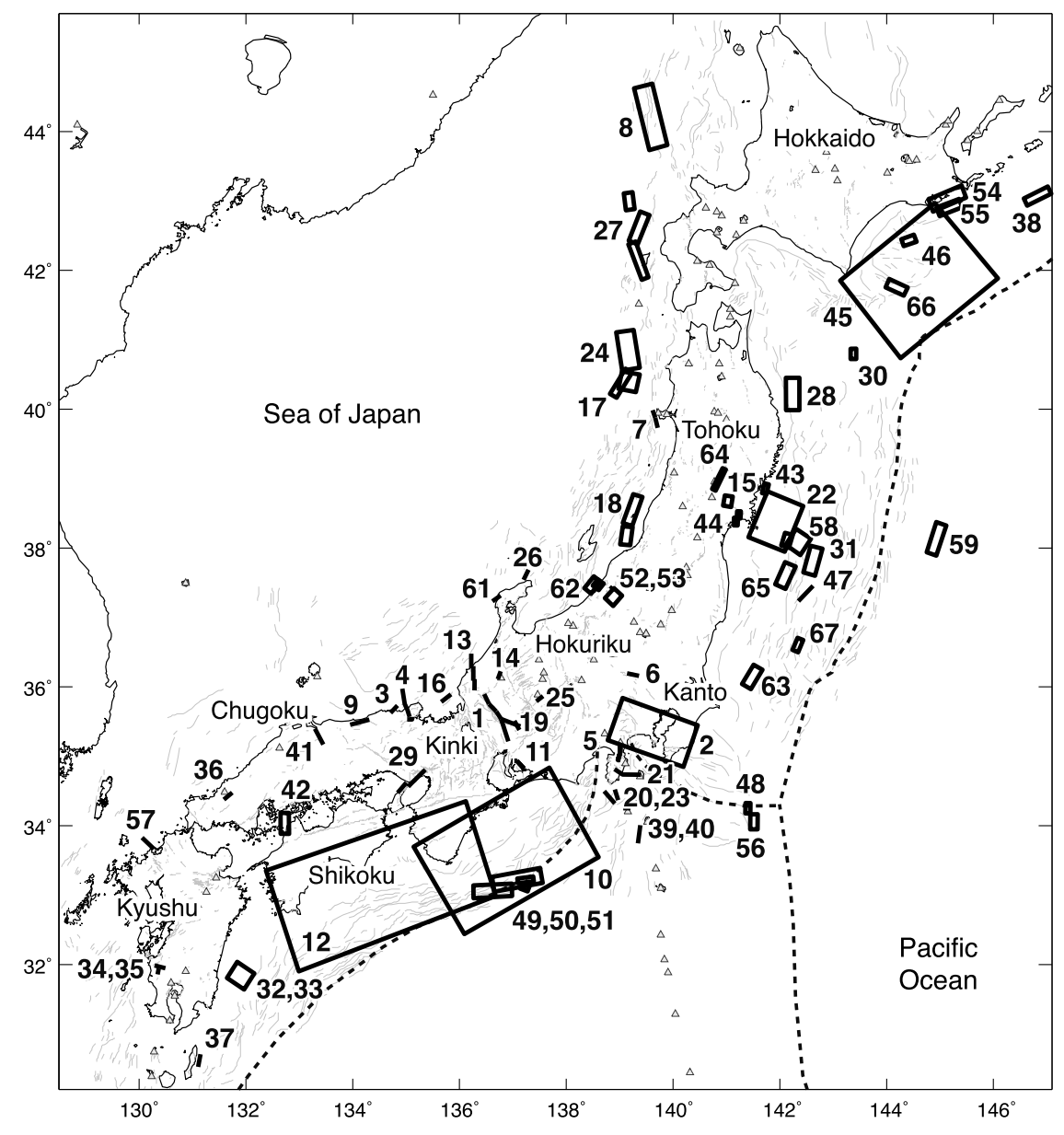

Fig. 3. Earthquake sources used for calculating the Coulomb stress changes ( $\triangle \mathrm{CFF})$ since AD 1891 . About a half of the earthquakes are modeled by variable slip distributions, obtained from previous papers. The number near each source corresponds to the ID number in Table 1 . Gray lines and triangles denote active faults and volcanoes, respectively. The dashed line indicates plate boundary.

ten better explains the off-fault aftershock distribution than the specified fault approach. However the weakness of the "optimally-oriented faults" approach is its strong dependence on the assumed regional stress tensor, which is unknown in most cases.

Here we employ the "specified fault" approach, considering typical regional faulting mechanisms. Regarding the spatial variability of faulting mechanisms, Terakawa and Matsu'ura (2008) well presented the gridded CMT solutions in and around the Japanese islands. However, since large inland earthquakes generally occur along the mapped active faults and the associated geologic structures nearby (the "structural controls" discussed by McCloskey et al.,
2005), here we mainly consider such structural controls defined by the regional active faults (Research Group for Active Faults of Japan, 1991) and geological structures, as well as the recent well-determined focal mechanisms (Fig. 4(a)). Hokkaido Island, and northern Honshu Island are dominated by the NS-striking reverse faulting earthquakes and active structures. Central Honshu Island has a mixture of both NS-trending reverse faults, NE-trending right-lateral strike-slip faults and NW-trending left-lateral strike-slip faults. There are numerous normal faulting earthquakes and structures associated with volcanoes and volcanic grabens in central Kyushu Island. We arbitrarily chose some of the typical regional mechanisms using both the focal mecha- 

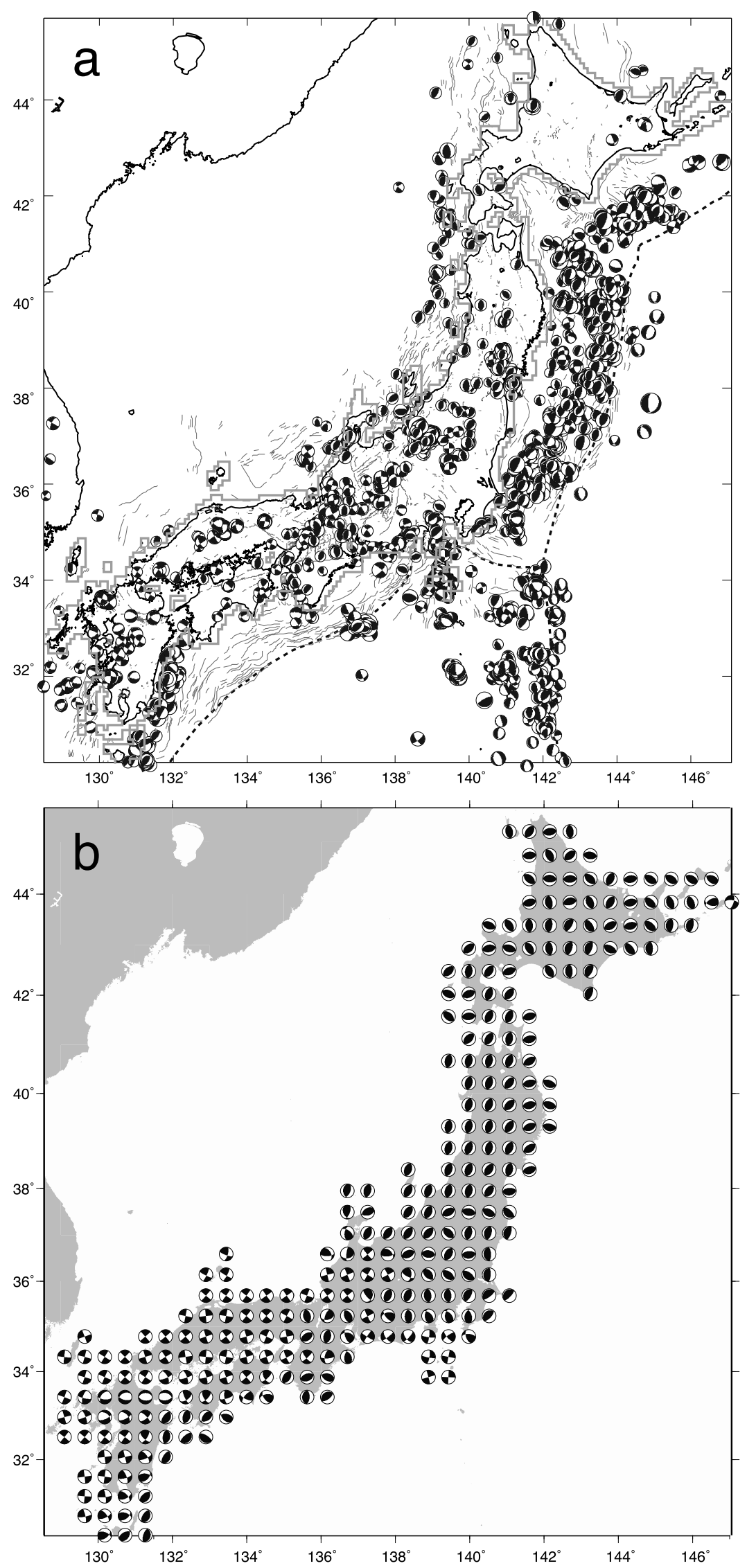

Fig. 4. (a) All well-determined focal mechanisms for $M \geq 3$ earthquakes, as detected by the F-net broadband network since 1997 (NIED, 2010 ), and mapped active faults (Research Group for Active Faults of Japan, 1991). Dashed line shows plate boundary. (b) Smoothed faulting mechanisms taking the earthquake focal mechanisms and active structures (Fig. 4(a)) into consideration. Both nodal planes are used as receiver faults for our Coulomb stress calculations. Note that the beach ball spacing in this figure is sparser than the actual grid space of the CSEP Japan for visualization purposes. 


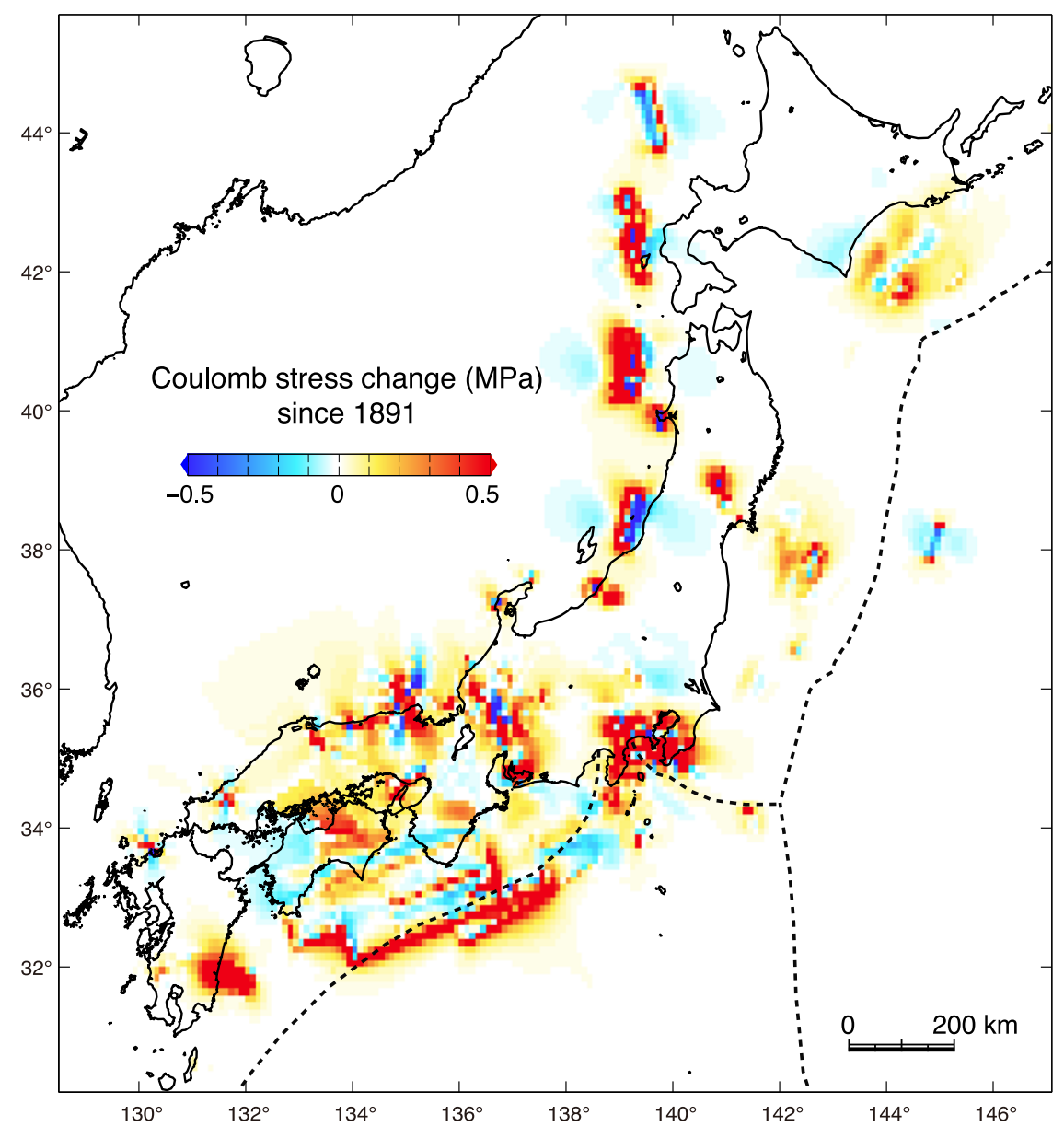

Fig. 5. Spatial summation of $\triangle \mathrm{CFF}$ caused by the large earthquakes since 1891, listed in Table 1 and shown in Fig. 3 . Stresses are resolved on two assumed nodal planes (Fig. 4(b)) and the maximum values through the seismogenic depth of 5-15 km are chosen. Dashed line indicates plate boundary.

nism and active fault information and smooth out these typical focal mechanisms onto the CSEP Japan grid (Fig. 4(b)). We then prepare two spatially gridded matrices for both nodal planes of the focal mechanism solution. The larger $\triangle \mathrm{CFF}$ value between those obtained for both nodal planes at each node is picked up to represent the local Coulomb value (Fig. 5).

\subsection{Time-dependent rate/state friction process}

To construct the time dependent evolution of seismicity, we tag by a time stamp the $\triangle \mathrm{CFF}$ matrix associated with each large earthquake. Each node of the CSEP Japan grid experienced the stress perturbations at the times of the 67 events but has different $\triangle \mathrm{CFF}$ values. The stress history at a node is illustrated as multiple steps (Fig. 2). To express the state of nucleation on faults in each gridded area, the rate and state friction law of Dieterich (1994) is employed. We use the expression for seismicity rate $R$ as a function of the state variable $\gamma$ under a tectonic secular shear stressing rate $\dot{\tau}$. Under constant shear stressing rate at each node (stressing rate is stable in time but variable in space in our model), $\gamma$ reaches the steady state, and is expressed as

$$
\gamma_{0}=\frac{1}{\dot{\tau}} \text {. }
$$

At steady state, the seismicity rate $R$ is equivalent to the background rate $r$ because $R$ is calculated from the follow- ing relation

$$
R=\frac{r}{\gamma \dot{\tau}}
$$

In the absence of a stress perturbation, the seismicity rate is assumed constant. We start with this stable condition. We then index the state variable $\gamma$ with time. If an earthquake strikes, it imposes a sudden stress step $\triangle \mathrm{CFF}$, and the state variable $\gamma_{n-1}$ changes to a new value $\gamma_{n}$

$$
\gamma_{n}=\gamma_{n-1} \exp \left(\frac{-\Delta \mathrm{CFF}}{A \sigma}\right)
$$

where $A \sigma$ is a constitutive parameter times the effective normal stress, assumed to be $0.05 \mathrm{MPa}$ (Toda and Stein, 2003). To seek the seismicity at the time of the stress step, we substitute the new state variable in (4). In rate/state friction there is a nonlinear dependence of the time to instability on stress change. A stress increase on a fault causes $\gamma$ to drop, so the fault slips at a higher rate, yielding a higher rate of seismicity (Fig. 2). Conversely, a sudden stress drop causes $\gamma$ to jump, lowering the rate of seismicity. The seismicity rate change is transient and eventually recovers, corresponding to a gradual evolution of $\gamma$, which for the next time step $\Delta t$ is given by

$$
\gamma_{n+1}=\left[\gamma_{n}-\frac{1}{\dot{\tau}}\right] \exp \left[\frac{-\Delta t \dot{\tau}}{A \sigma}\right]+\frac{1}{\dot{\tau}}
$$




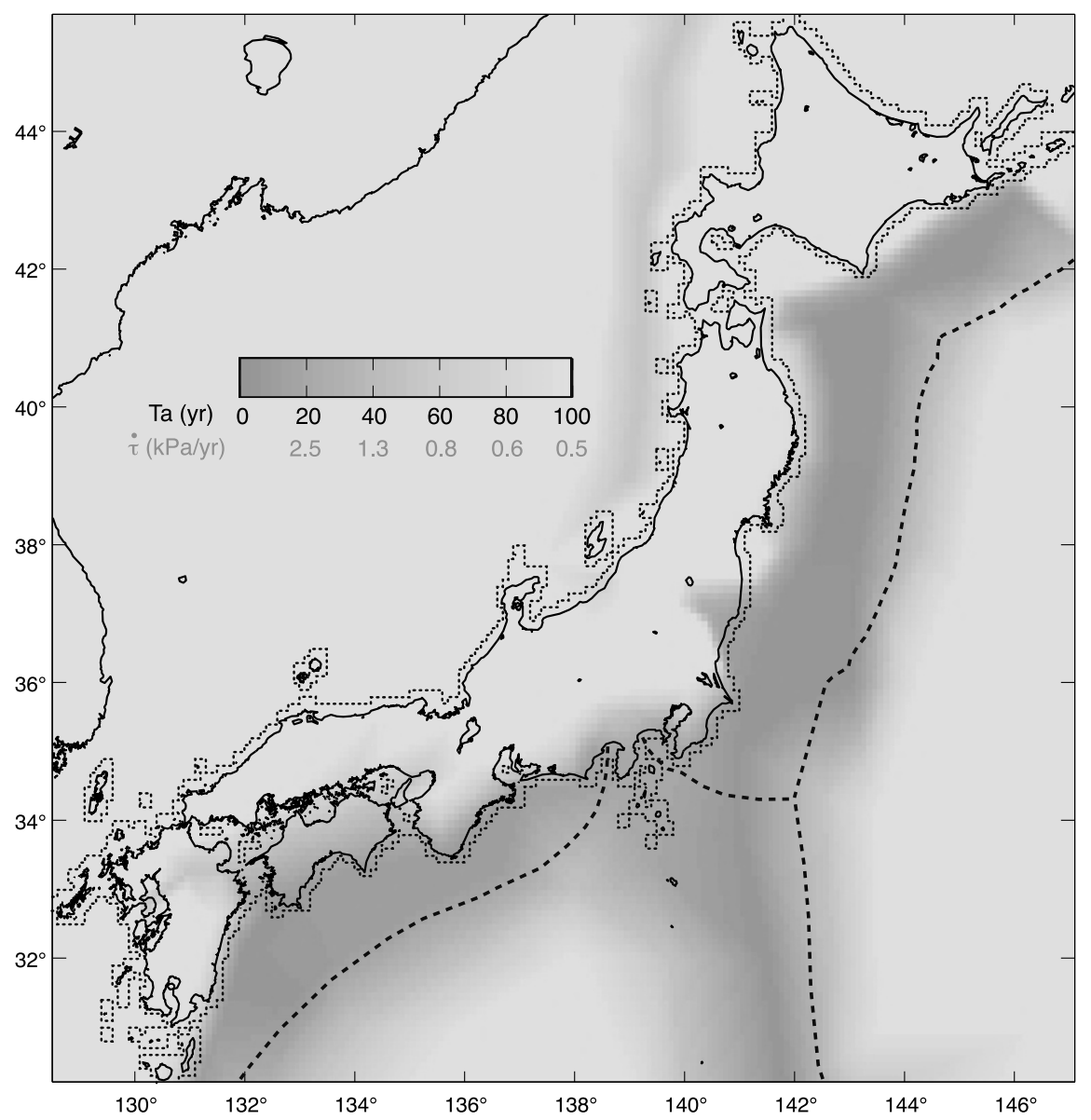

Fig. 6. Assumed aftershock duration $\left(t_{\mathrm{a}}\right)$ map. Corresponding stressing rate $\dot{\tau}$ with presumed $A \sigma$, is inversely proportional to $t_{\mathrm{a}}$, for which the scale is shown below the legend bar. Dotted lines enclose the CSEP Japan inland test area.

In rate and state friction, the duration of the transient effect, in other words the aftershock duration $t_{\mathrm{a}}$, is related to $A \sigma$ through

$$
t_{\mathrm{a}}=\frac{A \sigma}{\dot{\tau}} .
$$

Given sufficient time (e.g., decades to centuries), the effect of all but the largest stress changes disappears on the most slowly stressed faults. One can easily guess that the stressing rate is near the maximum along the plate interface and diminishes as a function of distance from the interface. Although the stressing rate is not practically measurable, the duration of aftershocks $t_{\mathrm{a}}$ indirectly justifies such rough estimation with Eq. (6): observed aftershock duration of a megathrust subduction event is much shorter than the one for an inland mainshock (figure 3 in Dieterich, 1994). Since we assume that $A \sigma$ is constant throughout time and space, the stressing rate $\dot{\tau}$ is in inverse proportion to the aftershock duration $t_{\mathrm{a}}$.

We arbitrarily assign the spatially variable $t_{\mathrm{a}}$ in Fig. 6 considering the distance from the plate interface and several aftershock sequences of the past large earthquakes. Since $t_{\mathrm{a}}$ in offshore east coast of northern Honshu and Hokkaido and coastal regions along the Nankai trough is short, the effect of stress changes on seismicity will disappear relatively soon. However, most of the CSEP mainland test regions sustain $t_{\mathrm{a}}$ of several decades to 100 years, which reproduces the long-lasting effect of coseismic stress changes.
The modeled $t_{\mathrm{a}}$ distribution also influences the initial condition of $\gamma$. According to Eq. (2), we start from the steady state variable $\left(\gamma_{0}\right)$, which is spatially nonhomogeneous: subduction regions have initially lower $\gamma$ whereas inland regions have higher $\gamma$ to begin with. We then compute $\gamma$ taking into account the $\triangle \mathrm{CFF}$ at discrete time steps using Eqs. (4) and (5). This process evolves $\gamma$ in time and space.

\subsection{Background seismicity rate}

To translate the effects of stress changes and their time dependency into seismicity, we have to know the real background seismicity rate $r$ in Eq. (3). Dieterich (1994) originally assumes that $r$ is the reference rate of seismicity before a stress change is applied. However, there are two different interpretations to define $r$ in the previously published papers that use real earthquake catalogs for retrospective seismicity forecasts. One is that $r$ is the actual seismicity rate before the stress perturbation (Toda et al., 2005). The other is that $r$ is well represented by the seismicity rate in a declustered catalog, in which any interactions between earthquakes are removed and the seismicity is a space- and time-independent Poisson process (Catalli et al., 2008). Cocco et al. (2010) redefined the "reference rate" as the $r$ value computed according to the former definition and adopted the "background rate" naming for the rates computed according to the later definition; they also discussed the differences and effects on seismicity forecasts 

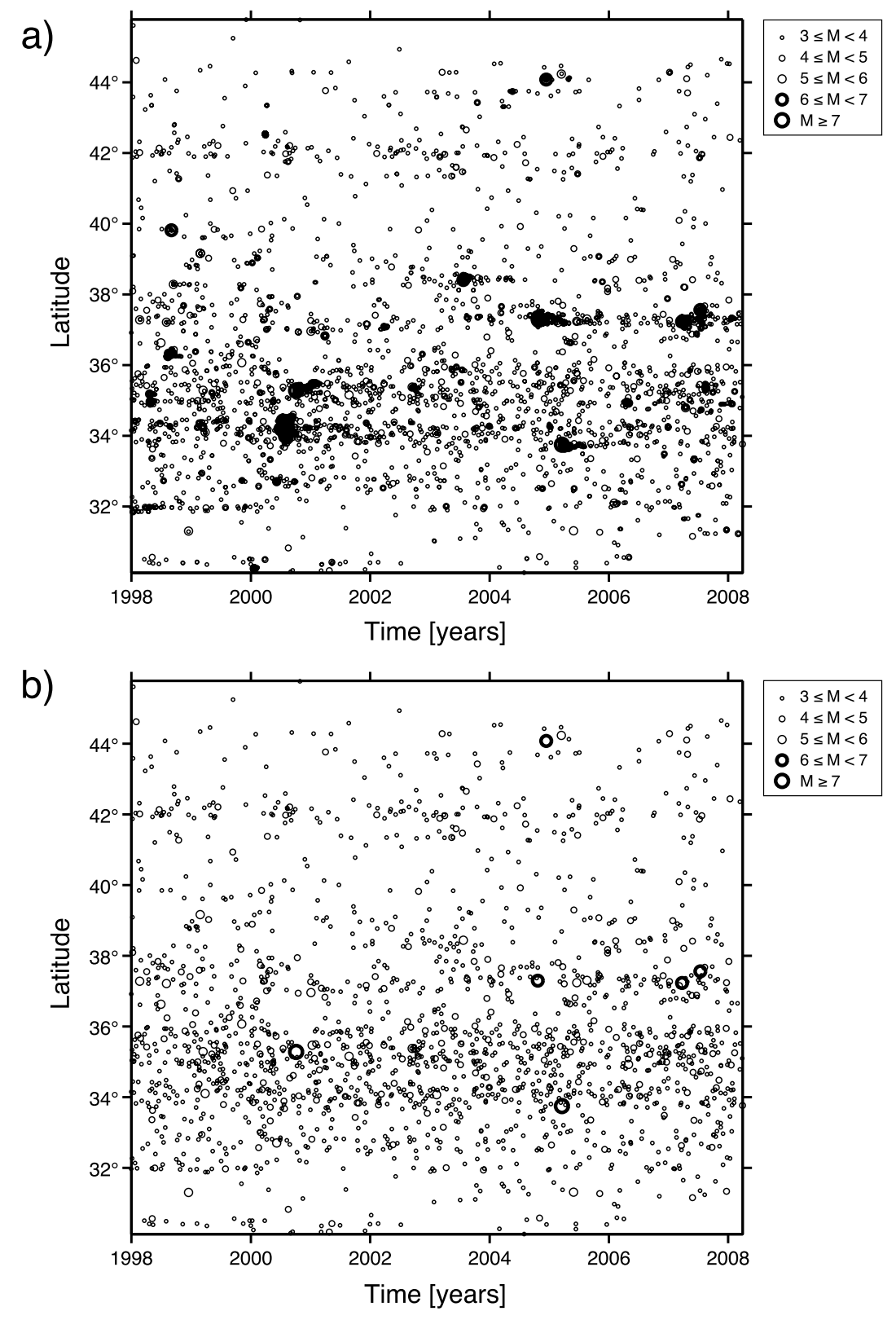

Fig. 7. Comparison between the original and declustered earthquake catalogs $(M \geq 3.0$, hypocenter depths $\leq 30 \mathrm{~km})$. (a) Time-latitude plot of seismicity for the original JMA catalog. (b) Time-latitude plot for the earthquake catalog declustered using the Marsan and Lengline (2008) algorithm.

of the two approaches. In our case, since the stress evolution starts from 1891, we cannot use the former approach due to the lack of a recorded earthquake catalog at such early times. We therefore apply the latter approach that requires using a declustering procedure.

Traditional declustering algorithms (e.g. Reasenberg, 1985) have the disadvantage of being based on a rather subjective choice of parameter values used to define the spatial and temporal extent of aftershock activity relative to the mainshock. Recently, more sophisticated methods (e.g., Zhuang et al., 2002) were proposed to perform stochastic declustering - that is, estimating the probability of an earthquake to be an aftershock of a previous event. The choice of parameters is made by maximum likelihood estimation (MLE), whose usage has been well justified in the statistical literature. Yet, however, such methods are modeldependent as the influence of a trigger earthquake is con- strained to follow a specific law, whose parameters must be inverted. Marsan and Lengline (2008) proposed a stochastic declustering method that estimates probabilities of triggered aftershocks with no a priori model. In this study we have applied the Marsan and Lengline (2008) algorithm to decluster the JMA catalog data (Figs. 7 and 8(a)).

As discussed in other studies (e.g., Nanjo et al., 2010), the completeness magnitude, $M_{\mathrm{c}}$, of the JMA catalog improved significantly from 1997, when JMA started processing earthquake data recorded by seismic networks of other institutions (NIED, Japanese Universities). Thus, to ensure general completeness, we selected the events with $M \geq 2.0$, depth shallower than $30 \mathrm{~km}$, which occurred from January 1998 to March 2008. The obtained catalog is the basis for further seismicity processing (this section and Section 2.7). By using a threshold magnitude of 2.0, however, we have noticed some regional "over-declustering" of the catalog 

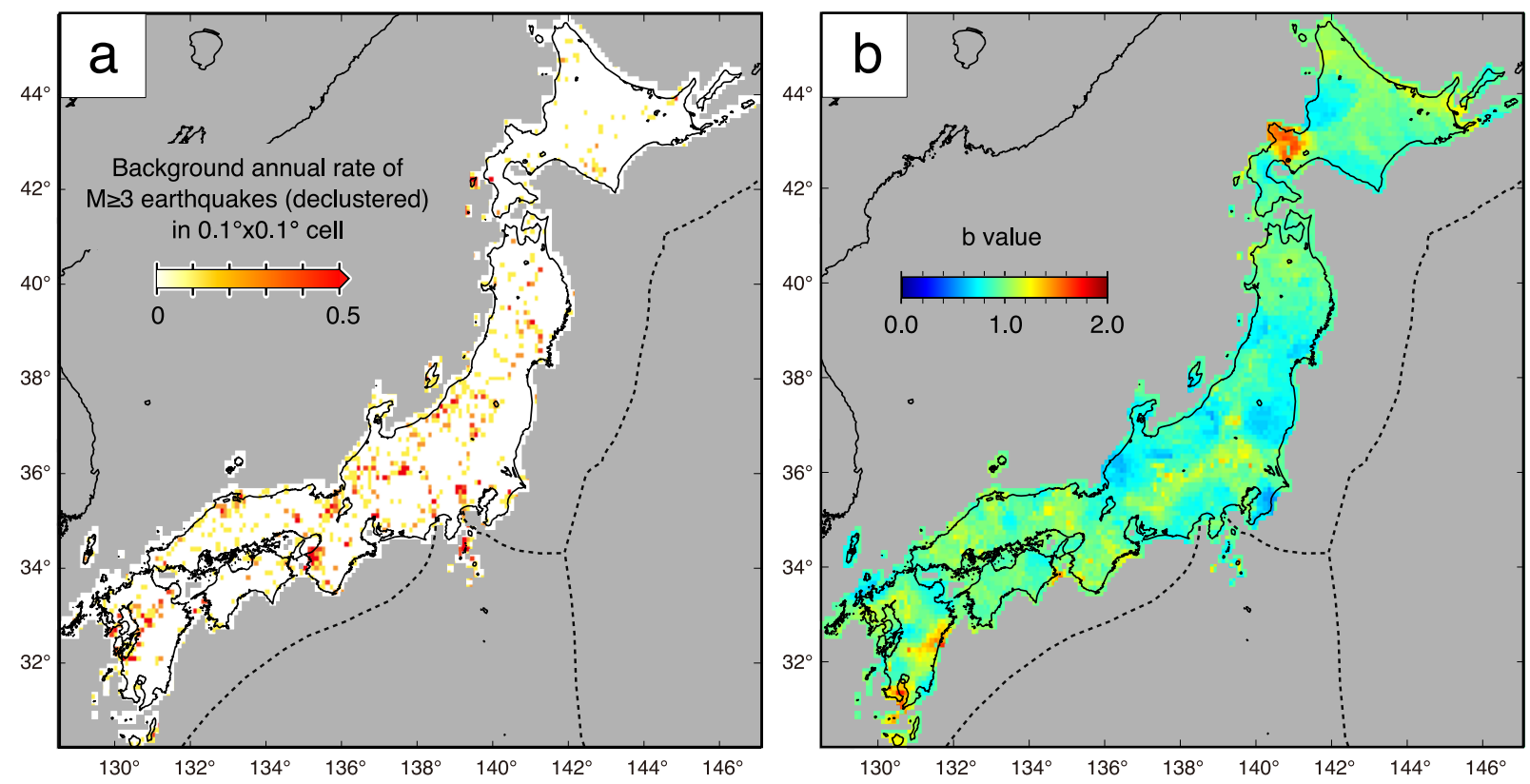

Fig. 8. (a) Background rate of seismicity $(M \geq 3.0)$ based on the JMA catalog (January 1998-March 2008) declustered by the algorithm of Marsan and Lengline (2008). (b) $b$-value distribution estimated by the maximum likelihood method, using the JMA catalog.

immediately following larger earthquakes $(M \geq 6.0)$. This is likely caused by higher completeness thresholds after the occurrence of larger events (e.g., Enescu et al., 2009). Therefore, we have decided to use for declustering earthquakes with $M \geq 3.0$. For such a threshold the incompleteness is minimal and appears only within a couple of hours after larger earthquakes.

The distribution of probabilities (of being an aftershock) assigned for each earthquake in the selected JMA catalog concentrate near 0 or $100 \%$. The bi-modal distribution suggests a rather clear separation between background events and aftershocks. Indeed, only a very small fraction of events (2\%) have probabilities in the $10 \%$ to $90 \%$ range. Similar results have been reported in other studies using stochastic declustering (e.g., Wu, 2010). Here we have considered as aftershocks the earthquakes with associated probabilities larger than $50 \%$, as this is considered a natural choice from a statistical point of view (see also Console et al., 2010). The clustered catalog (i.e., the catalog that contains the aftershocks) accounts for $81 \%$ of the total amount of events. For comparison, Marsan and Lengline (2008), who analyze the earthquake catalog of the Southern California Earthquake Data Center (threshold magnitude 3.0), report an amount of $19.5 \%$ background events. The examination of cumulative number plots for the original, declustered and clustered catalogs also suggests that the declustering worked well. We present in Fig. 7(a) and (b) timelatitude plots of seismicity for the original and the declustered catalog, respectively. It is noticed that the strong clustering (aftershocks) after the occurrence of relatively large events is removed well by declustering. The annual rates of declustered seismicity in $0.1^{\circ} \times 0.1^{\circ}$ cells, however, are adjusted by the following three-step treatment. 1) First, we apply a Gaussian smoothing, using a vertical cylinder of 5-km radius, to our data. 2) Then, the grid nodes of zero seismicity rates are replaced by $20 \%$ of the minimum rate, assum- ing that a ten-year observation period is not long enough to evaluate the background seismicity. 3) The total number of declustered earthquakes collected from all cells in about 10 years are calibrated to be equal to the total number of earthquakes in the original JMA catalog, keeping the spatial variability unchanged. The spatial distribution of rates after declustering does not show any obvious local clustering (Fig. 8(a)). Even in the areas of past large events which occurred before 1998 (e.g., the $1995 M=7.3$ Kobe earthquake; the $1983 M=7.7$ Nihonkai-chubu earthquake), there is no significant residual clustering (i.e., un-eliminated aftershocks).

\section{7 $b$-value estimates and frequency of large earth- quakes}

To achieve the goal of the CSEP Japan test, we must forecast the number of $M \geq 5.0$ earthquakes at each node of a grid with a spacing of $0.1^{\circ}$ by $0.1^{\circ}$. Although there are some papers pointing out significant $b$-value changes after a large mainshock (e.g., Wiemer et al., 2002) and large earthquakes may follow the characteristic earthquake model (Schwartz and Coppersmith, 1984), we can simply extrapolate the rate of small earthquakes to the rate of large earthquakes as a first approximation, following the procedure in Toda et al. (2005).

Due to the sensitivity of $b$-value estimates to the magnitude of completeness, $M_{\mathrm{c}}$, of the data, we have slightly increased the magnitude threshold of the analyzed catalog to 2.2. Moreover, as explained below, $M_{\mathrm{c}}$ was checked locally. We have computed the $b$-value at each node of the $0.1^{\circ} \times$ $0.1^{\circ}$ grid by sampling the closest 100 earthquakes, determining $M_{\mathrm{c}}$, and then computing the $b$-value for earthquakes with magnitudes above $M_{\mathrm{c}}$, using a maximum likelihood procedure (Aki, 1965). The magnitude of completeness was estimated as the magnitude for which $95 \%$ of the data can be modeled by a power-law fit, following the procedure of Wiemer and Wyss (2000). For the nodes where the number 

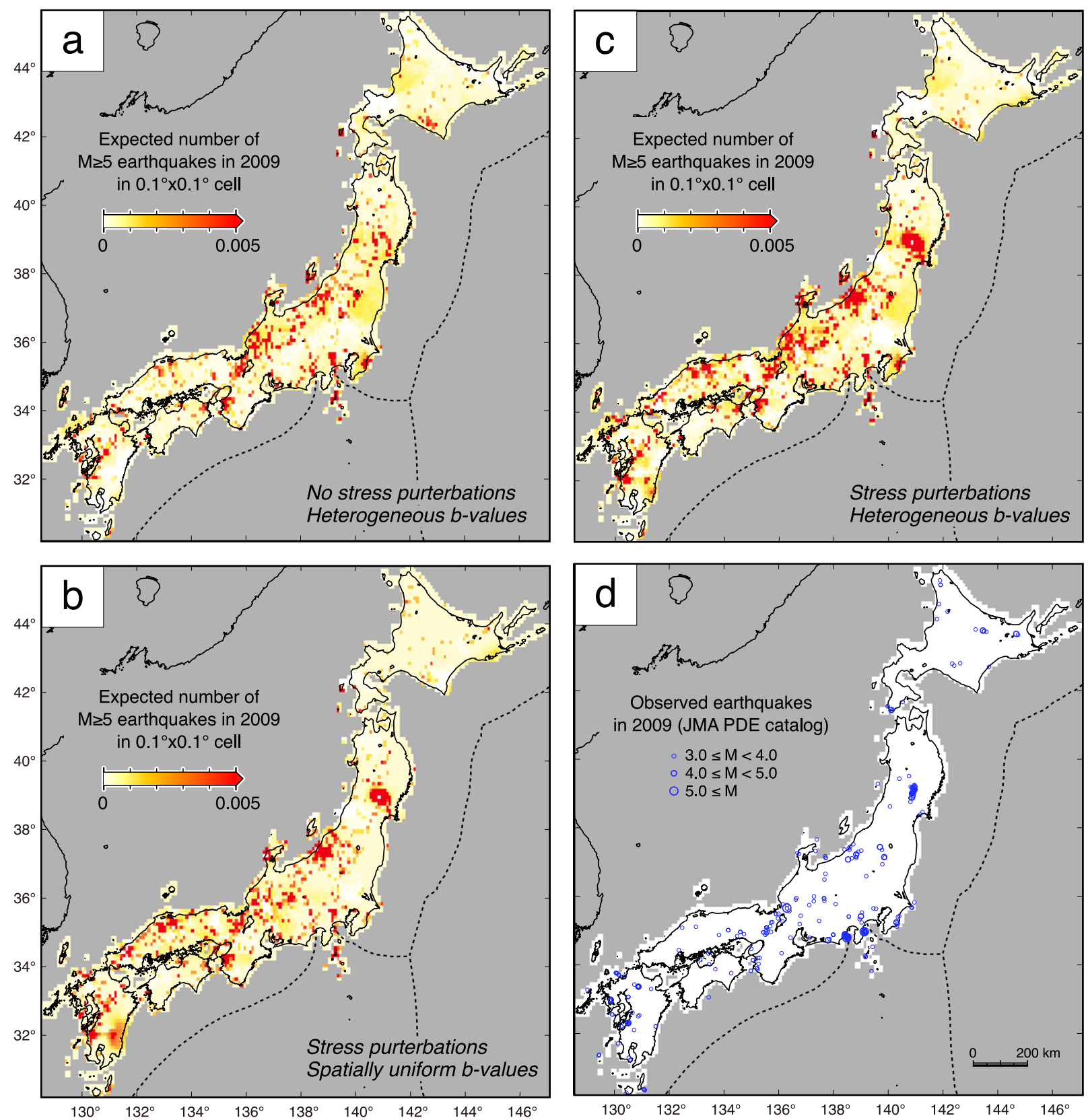

Fig. 9. (a) Expected number of $M \geq 5$ earthquakes in 2009, calculated from the combination of background rate of $M \geq 3$ shocks and spatially variable $b$-values. Note that no coseismic stress changes are considered for calculations to obtain the results in this figure. In other words, all $\Delta \mathrm{CFF}$ values for all the large earthquakes are assumed to be zero. (b) Expected number of $M \geq 5$ earthquakes in 2009 reproduced by our method but with the spatially constant $b$-value $(b=0.92)$. Note that the influence of the stress perturbations due to the historical earthquakes results in different forecasted rates compared to the case of no-stress-effect (Fig. 9(a)). (c) Expected number of $M \geq 5$ earthquakes in 2009 reproduced by our method with spatially variable $b$-value. (d) Earthquakes observed in 2009, in mainland Japan. On-fault and off-fault aftershocks of the recent inland large earthquakes can be reproduced by our approach. However, temporal swarm activities and high rate of continuous seismicity near Sagami and Suruga troughs in Izu and Kanto regions are hardly forecasted.

of sampled earthquakes with magnitudes above $M_{\mathrm{c}}$ was less than 50 , the $b$-value was not calculated. In the maximum likelihood procedure, the range of $b$-values is between 0.53 and 1.73, with an average value of 0.92 (Fig. 8(b)). For the nodes where the $b$-value could not be computed due to completeness issues, an average $b$-value was assigned for our forecasting algorithm. For the Coulomb stress modeling we have sampled the stress changes within the $0-15 \mathrm{~km}$ depth interval. Our choice is motivated by the fact that most of the seismicity, including larger events, occurs within this depth interval. Regarding the $b$-value determination, an im- portant requirement is the completeness of the earthquake catalog. We therefore prefer using earthquake data for the whole depth range $(0-30 \mathrm{~km})$, which may include less wellresolved hypocenter locations. We have tested however the $0-15 \mathrm{~km}$ depth range for the frequency-magnitude calculations and found a similar $b$-value pattern, which suggests that our results are robust.

\section{Results}

Since the purpose of this paper is to introduce our rate/state Coulomb stress transfer model, we exemplify its 


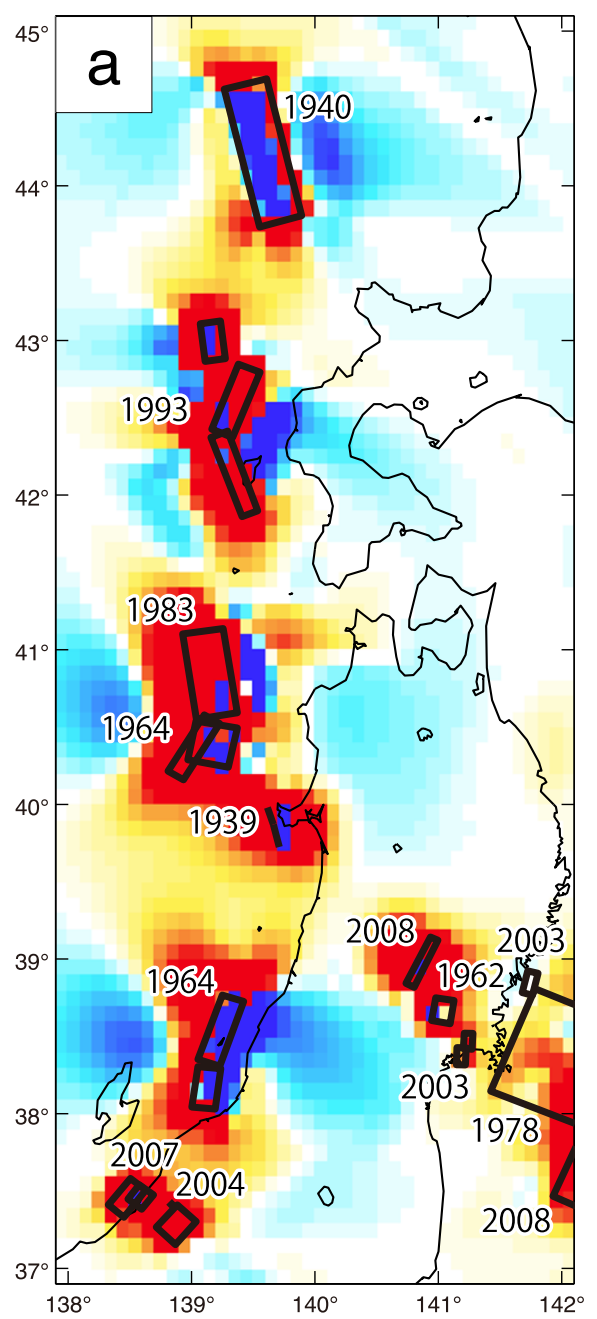

Coulomb stress change (MPa)

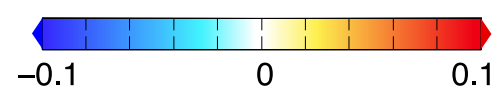

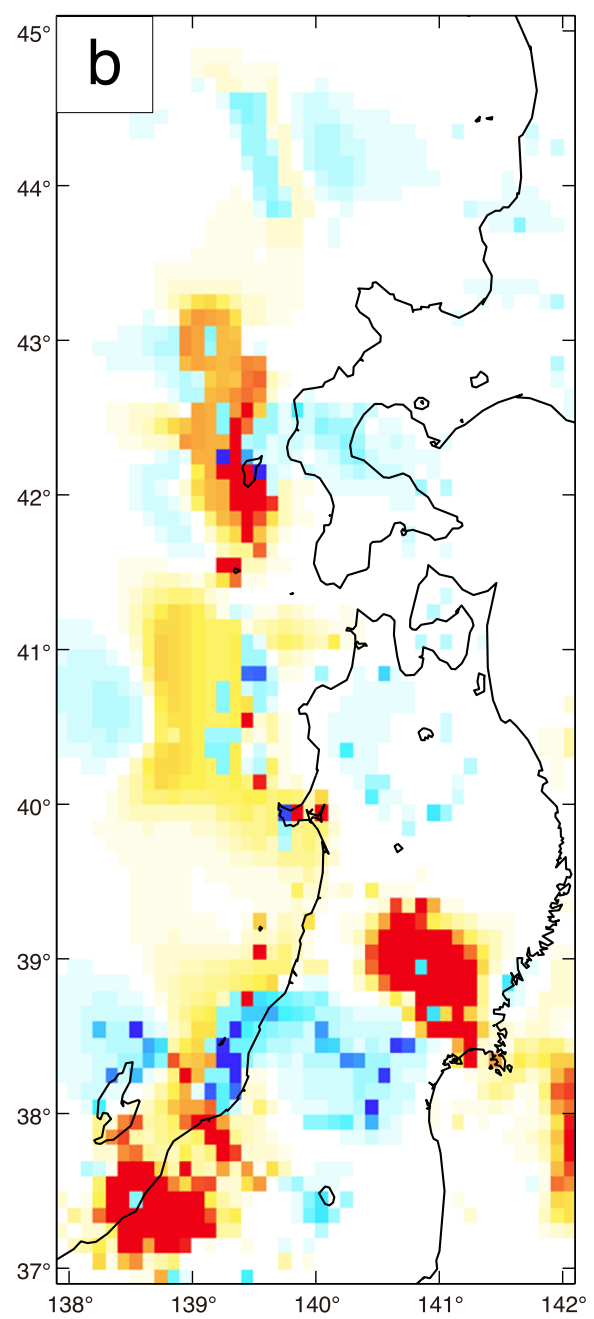

Changes in expected number of $M \geq 5$ events between "with" and "without" $\Delta$ CFF forecast (Fig. 9c - Fig. 9a)

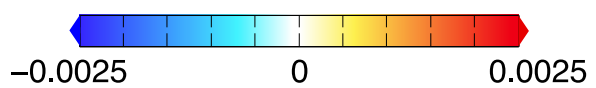

Fig. 10. Effect of stress shadow and its time-dependency in our forecasting model. (a) $\Delta$ CFFs caused by the large earthquakes in western Hokkaido and northern Honshu islands. The numbers are occurrence years of the earthquakes. (b) Differences between the expected numbers of $M \geq 5$ earthquakes by considering and by not considering the stress perturbations (the matrix of Fig. 9(c)-the matrix of Fig. 9(a)). Note that stress shadow effects in particular due to the 1964 Niigata earthquake are significant but they diminish as a function of elapsed time since the occurrence of the mainshock.

output for the year 2009, rather than analyzing the actual prospective forecasting, submitted and to be submitted to the test center.

Figure 9 shows the forecasted and observed number of earthquakes with magnitudes $M \geq 5.0$ in 2009. Figure 9(b) presents the forecasted frequency of $M \geq 5$ shocks using a homogeneous $b$-value of 0.92 , while Fig. 9 (c) is modeled using the heterogeneous $b$-value distribution of Fig. 8(b). Compared to the expected number of $M \geq 5$ shocks without any stress perturbation in Fig. 9(a), the stress perturbations due to the recent large earthquakes such as the 2008 Iwate-Miyagi Nairiku earthquake (\#64 in Table 1 and Fig. 3), 2007 Chuetsu-oki earthquake (\#62), 2007 Noto Hanto earthquake (\#61), and 2004 Chuetsu earthquake (\#52 and \#53) significantly amplify the background seismicity (Fig. 8(a)), and can reproduce (Figs. 9(b) and 9(c)) the on-fault and widely distributed off-fault aftershocks ob- served in 2009. Southern Kyushu Island has higher rates of expected seismicity that might be affected by the 1996 Kagoshima earthquakes (\#34 and \#35) and subduction zone earthquakes (\#32 and \#33). It is interesting to note that the seismicity in and around the 1891 Nobi earthquake is expected to be still higher (Fig. 9(c)) and slightly higher (Fig. 9(b)) than the background rate. The reason might be the widely disturbed stress due to the $M=8.0$ Nobi event and the subsequent shocks that might be triggered by the Nobi earthquake (e.g., \#11, \#13, \#14, \#19, and \#25).

The heterogeneous $b$-value distribution increases the spatial heterogeneity of $M \geq 5$ forecasts (Fig. 9(c)). Low $b$ value regions, in particular Hokuriku and southern Tohoku (Fig. 8(b)), are characterized by increased rates of larger shocks and may highlight the impacts of the stress perturbations. To see the stress perturbation effects for the heterogeneous $b$-value case, we compare Fig. 9(b) with Fig. 9(c). 
The high frequency of larger earthquakes in some regions is clearly due to the low $b$-value effect rather than the coseismic Coulomb stress changes (e.g., Tokai and Boso regions).

In general, to prove the effect of stress shadows on seismicity, high background seismicity and relatively long observation periods are required (e.g., Toda and Stein, 2003). In the maps showing the forecasted number of shocks, it is difficult to detect the lower frequency associated with the stress shadows. To clarify this issue, we subtract the $M \geq 5$ forecasts without the stress perturbations from the ones with stress perturbations (Fig. 10). Figure 10 focuses on the northern part of the CSEP test area (and further west) where NS-trending reverse faulting earthquakes along the eastern margin of the Japan Sea occurred since 1940. The $\triangle$ CFF map (Fig. 10(a)) shows significant increase of stresses along the earthquake sources and moderate decreases in inland regions, associated with the occurrence of the large earthquakes. In the case of the recent 2008 Iwate Miyagi Nairiku, 2004 Chuetsu, and 2007 Chuetsu-oki earthquakes stress shadows cannot be reproduced in our model. Corresponding decreases of $M \geq 5$ earthquakes expected in 2009 are mapped in Fig. 10(b). The modeled stress shadow associated with the 1964 Niigata earthquake still inhibits the seismicity in the regions west and east of the source (only one $M 3$ earthquake was observed in Fig. 9(d)). Figure 10 also clearly demonstrates the time dependent effect of stress changes on seismicity: the older events such as the 1940 shock do not remarkably change seismicity but the recent events occurred in 2000 s have strong impacts.

\section{Discussion and Conclusions}

\subsection{Possible advantages and differences from other cluster models}

We introduced so far our stress-based model and then showed forecast examples for $M \geq 5$ earthquakes in 2009 . Since our forecasts were recently submitted or are to be submitted to the CSEP Japan test center, rigorous testing is out of our scope here. Therefore we do not evaluate our approach modified for the CSEP test. However we show that our approach has several advantages - also pointed out by previous papers discussing the rate/state stress transfer (Toda and Stein, 2003; Catalli et al., 2008; Toda et al., 2005; Cocco et al., 2010)—relative to other statistical earthquake clustering models, such as the Omori-Utsu (Omori, 1894; Utsu, 1961), ETAS (Ogata, 1988) and STEP (Gerstenberger et al., 2004) models. Firstly, off-fault aftershock zones can be well simulated using rectangular finite fault sources rather than point sources. Secondly, areal patterns of triggered seismicity are also influenced by the regional dominant mechanisms of the potential earthquake sources ('receiver faults' in Fig. 4). Thirdly, imparted stresses associated with large earthquakes produce stress shadows that lead to a reduction of forecasted earthquakes. This may explain the general seismic quiescence, which the other cluster models cannot reproduce.

\subsection{Limitation}

There are considerable sources of uncertainty and unknown parameters associated with our forecasting model.
The earthquake stress changes include the slip model, the coefficient of friction, the depth dependence of stress, and the orientation and rake of the assumed receiver fault planes. Our approach to pick up the maximum stress changes from the values calculated at several depths and for the two possible receivers (i.e., the two possible fault planes that are consistent with a focal mechanism solution) clearly biases (towards increase) the number of forecasted rates. A significant flaw of the Coulomb approach that uses the finite source model is not to reproduce well the on-fault aftershocks; this effect may be "diluted" by the maximum stress pick-up but still influences the quantitative evaluation of the forecasted rates.

For the rate estimation of seismicity, additional uncertainties arise from the rate/state parameters (the aftershock duration, and the assumed spatially uniform value of $A \sigma$ ) and fundamental regional seismic characteristics (background rate of seismicity $r$ and $b$-values). The former parameters that are thoroughly discussed by Cocco et al. (2010) control the sensitivity of stress change and its time dependency. Although we roughly assign the spatial variability of $t_{\mathrm{a}}$, there might be strong regional and local heterogeneity. The latter estimates are based on the recent $10-\mathrm{yr}$ observed data, which may not be stationary and therefore may not be appropriate for forecasting. There are also several algorithms to estimate the background rate and $b$-value distribution that can also alter significantly the number of expected earthquakes.

\subsection{Future development for the shorter time forecast- ing interval}

Ideally our model should be fully automated for keeping "transparency", "controlled environment", and "reproducibility" (Schorlemmer and Gerstenberger, 2007). However, to have better resolution of stress changes, we definitely need detail and correct finite source fault models, which require human insight and inputs into the system. Such characteristics are not suitable for the short-term oneday prediction, which is one of the CSEP Japan forecastingclass options. The best prediction approach is to automate the process, but to correct "by hand" later, which is similar to hypocentral determination process. For the near future design of our model, in order to evaluate precursory activity prior to a large earthquake we may also need to take local stress perturbations into consideration. Stress changes due to frequently occurring moderate earthquakes can be automatically included into our algorithm as point sources. Our model can also simulate the secondary aftershocks and mimic the ETAS-type aftershock production. But the current CSEP grid of $0.1^{\circ} \times 0.1^{\circ}$ (roughly $10 \mathrm{~km} \times 10 \mathrm{~km}$ ) is much larger than the source dimension of $M$ 4-5 earthquakes and does not allow us to see the local impact of such smaller size events.

To reduce parameter uncertainties and assign them plausible values, it is better to follow a data assimilation type approach that considers feedback from the observed data. For more realistic forecast estimates, we consider incorporating in our future models possible ranges for the parameter values (e.g., Parsons et al., 2008; Aoi et al., 2010).

A fundamental limitation of our current model is that it only takes into account the stress perturbations but ignores 
the secular tectonic loading process of the large earthquake occurrence. As pointed out, such modeling may not be inappropriate for forecasting shallow crustal earthquakes in mainland Japan, due to the very low stressing rate. However, for longer-term forecasting like $10 \mathrm{yr}$ or $30 \mathrm{yr}$, additional stress due to tectonic loading, in particular in regions near subduction zones (e.g., Izu Peninsula), should not be ignored. More importantly, temporal high stress loading associated with volcanic activity and slow slip events along plate boundary raise the rate of seismicity and thus the forecasted number of large earthquakes (e.g., Toda et al., 2002; Toda and Matsumura, 2006). We will be able to incorporate such temporal increase rate of stress loading into our model in the near future.

Acknowledgments. We thank Naoshi Hirata, Hiroshi Tsuruoka and Kazu Nanjo for organizing the CSEP Japan project and recommending us to submit our paper to this special issue. Associate editor, Kazu Nanjo and two anonymous reviewers provided thoughtful comments that improved the manuscript. We are also indebted to Ross S. Stein who shares the fundamental ideas of the Coulomb and rate/state model and David Marsan who generously advised us on the use of his declustering algorithm. We thank the Japan Meteorological Agency for the earthquake catalog.

\section{References}

Abe, K., Seismic displacement and ground motion near a fault: The Saitama earthquake of September 21, 1931, J. Geophys. Res., 79, 43934399, 1974a.

Abe, K., Fault parameters determined by near- and far-field data: The Wakasa Bay earthquake of March 26, 1963, Bull. Seismol. Soc. Am., 64, 1369-1382, 1974b.

Abe, K., Dislocations, source dimensions and stresses associated with earthquakes in the Izu peninsula, J. Phys. Earth, 26, 253-274, 1978.

Aki, K., Maximum likelihood estimate of b in the formula $\log \mathrm{N}=\mathrm{a}-\mathrm{bM}$ and its confidence limits, Bull. Earthq. Res. Inst. Univ. Tokyo, 43, 237239, 1965.

Aoi, S., B. Enescu, W. Suzuki, Y. Asano, K. Obara, T. Kunugi, and K. Shiomi, Stress transfer in the Tokai subduction zone from the 2009 Suruga Bay earthquake in Japan, Nature Geosci., 3, 496-500, doi:10.1038/ngeo885, 2010.

Awata, Y., S. Toda, H. Kaneda, T. Azuma, H. Horikawa, M. Shishikura, and T. Echigo, Coastal deformation associated with the 2007 Noto Hanto earthquake, central Japan, estimated from uplifted and subsided intertidal organisms, Earth Planets Space, 60, 1059-1062, 2008.

Barka, A., The 17 August 1999 Izmit earthquake, Science, 285, 18581859, 1999.

Catalli, F., M. Cocco, R. Console, and L. Chiaraluce, Modeling seismicity rate changes during the 1997 Umbria-Marche sequence (central Italy) through rate- and state-dependent model, J. Geophys. Res., 113, B11301, doi:10.1029/2007JB005356, 2008.

Cocco, M., S. Hainzl, F. Catalli, B. Enescu, A. M. Lombardi, and J. Woessner, Sensitivity study of forecasted aftershock seismicity based on Coulomb stress calculation and rate- and state-dependent frictional response, J. Geophys. Res., 115, B05307, doi:10.1029/2009JB006838, 2010

Console, R., D. D. Jackson, and Y. Y. Kagan, Using the ETAS model for catalog declustering and seismic background assessment, Pure Appl. Geophys., doi:10.1007/s00024-010-0065-5, 2010.

Dieterich, J. A., constitutive law for rate of earthquake production and its application to earthquake clustering, J. Geophys. Res., 99, 2601-2618, 1994.

Enescu, B., J. Mori, M. Miyazawa, and Y. Kano, Omori-Utsu law c-values associated with recent moderate earthquakes in Japan, Bull. Seismol. Soc. Am., 99(2A), 884-891, doi:10.1785/0120080211, 2009.

Fukao, Y. and M. Furumoto, Mechanism of large earthquakes along the eastern margin of the Japan Sea, Tectonophysics, 25, 247-266, 1975.

Fukuyama, E. and K. Irikura, Rupture process of the 1983 Japan Sea (Akita-Oki) earthquake using a waveform inversion method, Bull. Seismol. Soc. Am., 76, 1623-1640, 1986.

Geospatial Information Authority of Japan (GSI), Source fault model of the May 26, 2003 Miyagiken-oki earthquake, http://www.gsi.go.jp/ common/000034410.gif, 2003 (in Japanese).

Geospatial Information Authority of Japan (GSI), Source fault model of the August 16, 2005 Miyagiken-oki earthquake, http://www.gsi.go.jp/ common/000037132.pdf, 2005 (in Japanese).

Geospatial Information Authority of Japan (GSI), Source fault model of the July 16, 2007 Niigata-ken-chuetsu-oki earthquake, http://www. gsi.go.jp/common/000037099.pdf, 2007 (in Japanese).

Gerstenberger, M., S. Wiemer, and L. Jones, Real-time forecasts of tomorrow's earthquakes in California: a new mapping tool, U.S. Geological Survey, Open-File Report 2004-1390, 39pp, 2004.

Hainzl, S., B. Enescu, M. Cocco, J. Woessner, F. Catalli, R. Wang, and F. Roth, Aftershock modeling based on uncertain stress calculations, $J$. Geophys. Res., 114, B05309, doi:10.1029/2008JB006011, 2009.

Hikima, K. and K. Koketsu, Source processes of the foreshock, mainshock and largest aftershock in the 2003 Miyagi-ken Hokubu, Japan, earthquake sequence, Earth Planets Space, 56, 87-93, 2004.

Hikima, K. and K. Koketsu, Rupture processes of the 2004 Chuetsu (mid-Niigata prefecture) earthquake, Japan: A series of events in a complex fault system, Geophys. Res. Lett., 32, L18303, doi:10. 1029/2005GL023588, 2005.

Horikawa, H., Earthquake doublet in Kagoshima, Japan: Rupture of asperities in a stress shadow, Bull. Seismol. Soc. Am., 91, 112-127, 2001.

Horikawa, H., Rupture process of the 2005 west off Fukuoka prefecture, Japan, earthquake, Earth Planets Space, 58, 87-92, 2006.

Ichinose, G. A., P. Somerville, H. K. Thio, S. Matsushima, and T. Sato, Rupture process of the 1948 Fukui earthquake (M 7.1) from the joint inversion of seismic waveform and geodetic data, J. Geophys. Res., 110(B5), B05301, doi:10.1029/2004JB003437, 2005.

Ide, S., Source process of the 1997 Yamaguchi, Japan, earthquake analyzed in different frequency bands, Geophys. Res. Lett., 26, 1973-1976, 1999.

Iwata, T. and H. Sekiguchi, Source process and near-source ground motion during the 2000 Tottori-ken Seibu earthquake, Chikyu, 38, 182-188, 2002 (in Japanese).

Kikuchi, M., M. Nakamura, and K. Yoshikawa, Source rupture processes of the 1944 Tonankai earthquake and the 1945 Mikawa earthquake derived from low-gain seismograms, Earth Planets Space, 55, 159-172, 2003

King, G. C. P., R. Stein, and J. Lin, Static stress changes and the triggering of earthquakes, Bull. Seismol. Soc. Am., 84, 935-953, 1994.

Mai, M., The database of finite-source rupture models, http://www. seismo.ethz.ch/srcmod/, 2007.

Marsan, D. and O. Lengline, Extending earthquakes' reach through cascading, Science, 319, 1076-1079, 2008.

Matsuhashi, Y., K. Yukawa, and H. Sato, Horizontal displacements accompanied with the Niigata earthquake of 1964 and its fault model, J. Seismol. Soc. Jpn. (Zisin), 40, 619-622, 1987 (in Japanese).

Matsu'ura, M., Inversion of geodetic data, Part II, Optimal model of conjugate fault system for the 1927 Tango earthquake, J. Phys. Earth, 25, 233-255, 1977.

McCloskey, J., S. S. Nalbant, and S. Steacy, Earthquake risk from coseismic stress, Nature, 434, 291, 2005.

Mikumo, T. and M. Ando, A search into the faulting mechanism of the 1891 great Nobi earthquake, J. Phys. Earth, 24, 63-87, 1976.

Mikumo, T., H. Wada, and M. Koizumi, Seismotectonics of the Hida region, central Honshu, Japan, Tectonophysics, 147, 95-119, 1988.

Nanjo, K. Z., T. Ishibe, H. Tsuruoka, D. Schorlemmer, Y. Ishigaki, and N. Hirata, Analysis of the completeness magnitude and seismic network coverage of Japan, Bull. Seismol. Soc. Am., 100, 3261-3268, doi:10.1785/0120100077, 2010 .

National Research Institute for Earth Science and Disaster Prevention (NIED), NIED Earthquake Mechanism Search (NIED Fnet, Broadband Seismograph Network), http://www.fnet.bosai.go.jp/ event/search.php?LANG=en, 2010.

Ogata, Y., Statistical model for earthquake occurrences and residual analysis for point processes, J. Am. Stat. Assoc., 83, 9-27, 1988.

Okada, Y., Fault mechanism of the Izu-Oshima-kinkai earthquake of 1978 , as inferred from the crustal movement data, Bull. Earthq. Res. Inst. Univ. Tokyo, 53, 823-840, 1978.

Okada, Y., Internal deformation due to shear and tensile faults in a halfspace, Bull. Seismol. Soc. Am., 82, 1018-1040, 1992.

Omori, F., On after-shocks of earthquakes, J. Coll. Sci. Imp. Univ. Tokyo, 7, 111-200, 1894.

Parsons, T., Global Omori law decay of triggered earthquakes: Large aftershocks outside the classical aftershock zone, J. Geophys. Res., 107(B9), 2199, doi:10.1029/2001JB000646, 2002. 
Parsons, T., C. Ji, and E. Kirby, Stress changes from the 2008 Wenchuan earthquake and increased hazard in the Sichuan basin, Nature, 454, 509510, doi:10.1038/nature07177, 2008.

Reasenberg, P., Second-order moment of Central California seismicity, $J$. Geophys. Res., 90, 5479-5495, 1985.

Research Group for Active Faults of Japan, Active Faults in Japan, sheet maps and inventories, rev. ed., 437 pp., Univ. of Tokyo Press, Tokyo, 1991.

Satake, K., Re-examination of the 1940 Shakotan-Oki earthquake and the fault parameters of the earthquakes along the eastern margin of the Japan Sea, Phys. Earth Planet. Inter., 43, 137-147, 1986.

Satake, K., Depth distribution of coseismic Slip along the Nankai Trough, Japan, from joint inversion of geodetic and tsunami data, J. Geophys. Res., 98, 4553-4565, 1993.

Sato, H., A study of horizontal movement of the earth crust associated with destructive earthquakes in Japan, Bull. Geogr. Surv. Inst., 19, 89-130, 1973.

Sato, R., K. Abe, Y. Okada, K. Shimazaki, and Y. Suzuki, Handbook of Source Fault Parameters for Large Earthquakes in and around Japanese Islands, Kajima Institute Publishing Co., Ltd., 390 pp, 1989 (in Japanese).

Sato, R., S. Ide, Y. Kakei, and T. Yokoi, Catalog of Heterogeneous Source Fault Parameters of Japan's Large Earthquakes Occurred in 1980-1995, Association for the Development of Earthquake Prediction, 111 pp., 1999 (in Japanese).

Sato, R. and K. Koketsu, Catalog of Heterogeneous Source Fault Parameters of Japan's Large Earthquakes Occurred in 1944-2003, Association for the Development of Earthquake Prediction, 111pp., 2005 (in Japanese).

Schorlemmer, D. and M. C. Gerstenberger, RELM testing center, Seismol. Res. Lett., 78, 30-36, 2007.

Schorlemmer, D., J. D. Zechar, M. Gerstenberger, N. Hirata, K. Nanjo, and T. Jordan, Results from earthquake forecast testing in the Collabratory for the Study of Earthquake Predictability, Abstract of Japan Geoscience Union Meeting (JPGU) 2009, http://wwwsoc. nii.ac.jp/jepsjmo/cd-rom/2009cd-rom/program/session/pdf/S220/S220001_e.pdf, 2009.

Schwartz, D. P. and K. J. Coppersmith, Fault behavior and characteristic earthquakes: examples from the Wasatch and San Andreas fault zones, J. Geophys. Res., 89, 5681-5698, 1984.

Sekiguchi, H. and T. Iwata, Rupture process and strong motion during the 2001 Geiyo, Japan, earthquake, Chikyu, Special volume 38, 239-246, 2002 (in Japanese).

Steacy, S., J. Gomberg, and M. Cocco, Introduction to special section: Stress transfer, earthquake triggering, and time-dependent seismic hazard, J. Geophys. Res., 110, B05S01, doi:10.1029/2005JB003692, 2005.

Takada, Y., T. Kobayashi, M. Furuya, and M. Murakami, Coseismic displacement due to the 2008 Iwate-Miyagi Nairiku earthquake detected by ALOS/PALSAR: preliminary results, Earth Planets Space, 61, e9-e12, 2009.

Takeo, M., Rupture process of the 1980 Izu-Hanto-Toho-Oki Earthquake deduced from strong motion seismograms, Bull. Seismol. Soc. Am., 78, 1074-1091, 1988.

Takeo, M., Fault heterogeneity of inland earthquakes in Japan, Bull. Earthq. Res. Inst. Univ. Tokyo, 65, 541-569, 1990.

Takeo, M. and N. Mikami, Inversion of strong motion seismograms for the source process of the Naganoken-Seibu Earthquake of 1984, Tectonophysics, 144, 271-285, 1987.
Tanioka, Y., K. Satake, and L. Ruff, Total analysis of the 1993 Hokkaido Nansei-Oki Earthquake using seismic wave, tsunami, and geodetic data, Geophys. Res. Lett., 22, 9-12, 1995.

Tanioka, Y., K. Hirata, R. Hino, and T. Kanazawa, Slip distribution of the 2003 Tokachi-oki earthquake estimated from tsunami waveform inversion, Earth Planets Space, 56, 373-376, 2004.

Terakawa, T. and M. Matsu'ura, CMT data inversion using a Bayesian information criterion to estimate seismogenic stress field, Geophys. J. Int., 172, 674-685, 2008.

Toda, S. and S. Matsumura, Spatio-temporal stress states estimated from seismicity rate changes in the Tokai region, central Japan, Tectonophysics, 417, 53-68, 2006.

Toda, S. and R. S. Stein, Toggling of seismicity by the 1997 Kagoshima earthquake couplet: A demonstration of time-dependent stress transfer, J. Geophys. Res., 108(B12), 2567, doi:10.1029/2003JB002527, 2003.

Toda, S., R. S. Stein, and T. Sagiya, Evidence from the AD 2000 Izu islands earthquake swarm that stressing rate governs seismicity, Nature, 419, 58-61, 2002.

Toda, S., R. S. Stein, K. Richards-Dinger, and S. B. Bozkurt, Forecasting the evolution of seismicity in southern California: Animations built on earthquake stress transfer, J. Geophys. Res., 110, B05S16, doi:10.1029/2004JB003415, 2005.

Utsu, T., A statistical study on the occurrence of aftershocks, Geophys. Mag., 30, 521-605, 1961.

Wald, D. J., Slip history of the 1995 Kobe, Japan, earthquake determined from strong motion, teleseismic, and geodetic data, J. Phys. Earth, 44, 489-503, 1996.

Wald, D. J. and P. G. Somerville, Variable-slip rupture model of the great 1923 Kanto, Japan, Earthquake-Geodetic and body-wave-form analysis, Bull. Seismol. Soc. Am., 85, 159-177, 1995.

Wells, D. L. and K. J. Coppersmith, New empirical relationships among magnitude, rupture length, rupture width, rupture area, and surface displacement, Bull. Seismol. Soc. Am., 84, 974-1002, 1994.

Wiemer, S. and M. Wyss, Minimum magnitude of complete reporting in earthquake catalogs: examples from Alaska, the western United States and Japan, Bull. Seismol. Soc. Am., 90, 859-869, 2000.

Wiemer, S., M. Gerstenberger, and E. Hauksson, Properties of the aftershock sequence of the 1999 Mw 7.1 Hector Mine earthquake: Implications for aftershock hazard, Bull. Seismol. Soc. Am., 92, 1227-1240, 2002.

Wu, Z., A hidden Markov model for earthquake declustering, J. Geophys. Res., 115, B03306, doi:10.1029/2008JB005997, 2010.

Yagi, Y., M. Kikuchi, S. Yoshida, and Y. Yamanaka, Source process of the Hyuga-nada Earthquake of April 1, 1968 (Mjma 7.5), and its relationship to the subsequent seismicity, J. Seismol. Soc. Jpn. (Zisin), 51, 139-148, 1998 (in Japanese).

Yamanaka, Y. and M. Kikuchi, Asperity map along the subduction zone in northeastern Japan inferred from regional seismic data, J. Geophys. Res., 109(B7), B07307, doi:10.1029/2003JB002683, 2004.

Yoshioka, N., Mechanism for earthquake occurrence, crustal deformation, and tsunami, Master Thesis, Geophysical Department, Tokyo University, 1974.

Zhuang, J., Y. Ogata, and D. Vere-Jones, Stochastic declustering of spacetime earthquake occurrences, J. Am. Stat. Ass., 97, 458, 369-380, 2002.

S. Toda (e-mail: toda@rcep.dpri.kyoto-u.ac.jp) and B. Enescu 